\title{
Inferior Vena Cava Reconstruction for Nonseminomatous Germ Cell Tumor
}

\author{
Anand Raja ${ }^{1, \odot ~ K a n u j ~ M a l i k ~}{ }^{1}$ \\ ${ }^{1}$ Department of Surgical Oncology, Cancer Institute (WIA), Adyar, \\ Chennai, Tamil Nadu, India
}

Ind J Med Paediatr Oncol 2021;42:364-365.

A 30-year-old male presented with an abdominal lump and was diagnosed with nonseminomatous germ cell tumor (International Germ Cell Cancer Collaborative Group [IGCCCG] poor risk). The serum tumor markers at presentation were serum alpha fetoprotein (SAFP): $209.8 \mathrm{ng} / \mathrm{mL}$, serum beta-human chorionic gonadotropin (S $\beta-\mathrm{hCG}): 830009 \mathrm{mIU} / \mathrm{mL}$, and serum lactate dehydrogenase (SLDH): $2051 \mathrm{U} / \mathrm{L}$. The patient had a high pulmonary burden of disease and dyspnea, and hence four cycles of VIP (ifosfamide/etoposide/cisplatin) chemotherapy were administered. The administration of bleomycin was avoided. On re-evaluation of the contrast-enhanced computed tomography scan, our patient had multiple large residual retroperitoneal nodes with inferior vena cava (IVC) infiltration (-Fig. 1). The tumor markers had dropped to normal limits, SAFP: 6 ng/mL, Sß-hCG: $3.1 \mathrm{mIU} / \mathrm{mL}$, and SLDH: $210 \mathrm{U} / \mathrm{L}$. He underwent retroperitoneal lymph node dissection with IVC resection and reconstruction using expanded polytetrafluoroethylene (PTFE) graft. Intraoperatively, the infrarenal IVC was involved by the tumor for a length of $5 \mathrm{~cm}$, just proximal to the bifurcation, with no collateral formation. The tumor mass was dissected off from the abdominal aorta and the retroperitoneum, till it was attached only to IVC ( - Fig. $\mathbf{2 A}$ and $\mathbf{B}$ ). After gaining vascular control of bilateral renal veins
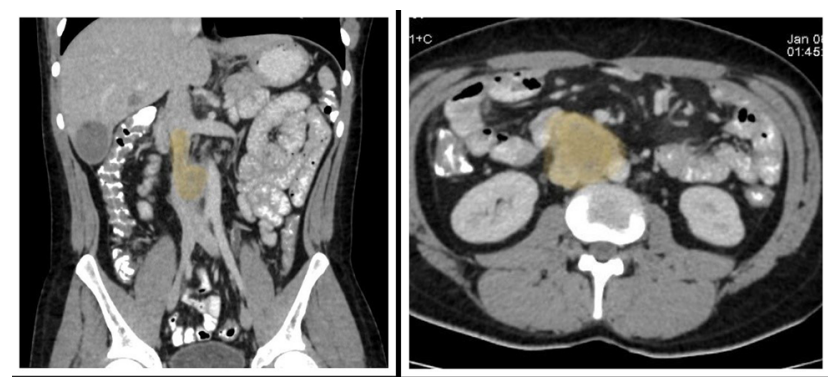

Fig. 1 Sagittal (A) and axial (B) view of contrast-enhanced computed tomography showing retroperitoneal nodal mass (yellow shaded) infiltrating inferior vena cava.

\begin{abstract}
Address for correspondence Anand Raja, MS, MCh (Surgical Oncology), Department of Surgical Oncology, Cancer Institute (WIA), No. 38 Sardar Patel Marg, Adyar, Chennai, Tamil Nadu 600020, India (e-mail: dr_anand@yahoo.com).
\end{abstract}

and proximal and distal IVC, 5000 IU of heparin was given and a vascular resection was performed. The lumbar venous tributaries were ligated and divided. The vein was reconstructed using expanded PTFE graft and anastomosis performed using 3-0 polypropylene sutures ( - Fig. 2C and D). The total IVC clamping time was 20 minutes. End-tidal $\mathrm{CO}_{2}$ was monitored intraoperatively to rule out any pulmonary thromboembolic event. As the IVC was clamped infrarenally, there was no fall in blood pressure noted during the entire procedure. Postoperative course was uneventful and patient was started on anticoagulants. The patency of graft was confirmed using Doppler study. The histopathology was suggestive of presence of viable tumor with IVC wall infiltration.

Postchemotherapy retroperitoneal lymph node dissection forms an integral part of management of testicular tumors.
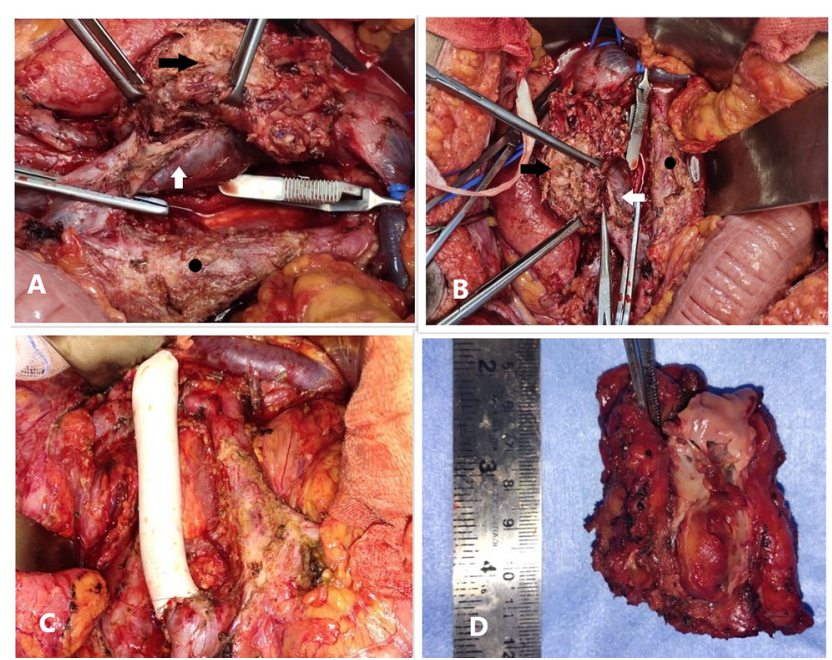

Fig. 2 (A and B) Intraoperative picture of tumor mass infiltrating inferior vena cava (IVC) wall (black arrow: tumor mass, white arrow: point of IVC infiltration, black circle: aorta). (C) Intraoperative picture post-IVC reconstruction using polytetrafluoroethylene graft. (D) Resected tumor specimen along with IVC wall.
DOI https://doi.org/ $10.1055 / \mathrm{s}-0041-1736681$ ISSN 0971-5851
(C) 2021. Indian Society of Medical and Paediatric Oncology

This is an open access article published by Thieme under the terms of the Creative Commons Attribution-NonDerivative-NonCommercial-License, permitting copying and reproduction so long as the original work is given appropriate credit. Contents may not be used for commercial purposes, or adapted, remixed, transformed or built upon. (https://creativecommons.org/licenses/by-nc-nd/4.0/).

Thieme Medical and Scientific Publishers Private Ltd. A-12, Second Floor, Sector -2, NOIDA -201301, India 
IVC involvement by residual tumor mandating surgical resection is reported in 7 to $11 \%$ cases. ${ }^{1}$ The proposed pathways leading to IVC involvement include direct vascular spread through right gonadal vein or lymphatic metastasis leading to external compression/infiltration. ${ }^{2}$ Donohue et al reported the largest series of 75 patients citing the following reasons for IVC resection: inability to remove tumor thrombus by cavotomy alone (33\%), tumor adherent to or invading the cava (58\%), and IVC occlusion by scar tissue $(8 \%){ }^{3}$ The presence of teratoma/viable tumor in $80 \%$ of such surgically resected specimen highlights the oncological significance of complete tumor clearance at the expense of vascular resection. Furthermore, $77 \%$ concordance was seen between the pathology of retroperitoneal node and tumor thrombus. ${ }^{4}$ This underlines the need for an aggressive approach for the management of residual disease. A mathematical model to predict the need for IVC intervention based on the residual tumor size and IGCCCG classification has been proposed; however, it needs validation. ${ }^{5}$ The need for IVC reconstruction is based on the presence of collateral vessels. In the presence of collaterals, resection of infrarenal IVC requires no reconstruction. In the absence of collaterals, expanded PTFE graft appears to be the conduit of choice as compared with the vein grafts. ${ }^{6}$ The complications reported specific to IVC resection include lower limb edema, ascites, chylothorax, deep venous thrombosis, pulmonary embolism, and renal insufficiency; however, these all generally resolve with time. ${ }^{3}$

\section{Note}

The study design complies with the Declaration of Helsinki ethical standards.

The data that support the findings of this study are available on request from the corresponding author.

\section{Declaration of Patient Consent}

The authors certify that they have obtained all appropriate patient consent forms.

\section{Financial Support}

Nil.

\section{Conflict of interest}

None declared.

\section{References}

1 Albers P, Melchior D, Müller SC. Surgery in metastatic testicular cancer. Eur Urol 2003;44(2):233-244

2 Choy DK, Yip SK, Cheng WS, Tan BS. Clinics in diagnostic imaging (44). Testicular tumour with retroperitoneal lymphadenopathy and inferior vena cava thrombosis. Singapore Med J 1999;40(12):756-759

3 Beck SDW, Lalka SG. Long-term results after inferior vena caval resection during retroperitoneal lymphadenectomy for metastatic germ cell cancer. J Vasc Surg 1998;28(5):808-814

4 Donohue JP, Thornhill JA, Foster RS, Bihrle R. Vascular considerations in postchemotherapy. Retroperitoneal lymph-node dissection: Part I-Vena cava. World J Urol 1994;12(4):182-186

5 Winter C, Pfister D, Busch J, et al. Residual tumor size and IGCCCG risk classification predict additional vascular procedures in patients with germ cell tumors and residual tumor resection: a multicenter analysis of the German Testicular Cancer Study Group. Eur Urol 2012;61(2):403-409

6 Mullen JC, Lemermeyer G, Tittley J, Ameli FM, Lossing AG, Jewett MA. Metastatic testicular tumor requiring inferior vena cava resection. Urology 1996;47(2):263-265 